\title{
From Ideas to Opportunities: Exploring the Construction of Technology-Based Entrepreneurial Opportunities
}

\author{
Ferran Giones, Zhao Zhou, Francesc Miralles, and Bernhard Katzy
}

\author{
"It's not the size of the dog in the fight," \\ it's the size of the fight in the dog.
}

Attributed to Mark Twain,

Author and humorist

\begin{abstract}
The transformation of business ideas into market opportunities is at the core of entrepreneurship. Nevertheless, the complexity of such a transformative process is seen to change depending on the variables influencing the opportunity-entrepreneur nexus. Although technology-entrepreneurship is regarded as a force of change and dynamism in socio-economic growth, it also depends upon an intricate process of opportunity development. The interest in understanding better how technology-based entrepreneurs simultaneously cope with technological uncertainty while trying to gain stakeholder support and access to resources, highlights a relevant research gap. The research described in this article uses the constructivist view to deepen our understanding of the technology-based entrepreneur's conceptualization of the opportunity as a process of social construction. Our results show how initial consensus-building efforts and iteration with knowledgeable peers are an essential part of the emergence of the opportunity, changing both entrepreneur's and stakeholders' perceptions of the early business idea. Consequently, our results provide evidence in support of policy programs and measures that favour social-construction support mechanisms to foster technology-based entrepreneurship.
\end{abstract}

\section{Introduction}

Establishing a resilient foundation for future economic and social growth has been a long-term goal of governments around the world. Policy makers have prioritized the initiatives that could provide further economic growth and dynamism. In this context, the promotion of technology-based entrepreneurship has often been the most sought-after outcome of such policies and their related programs. However, the results of such efforts have not always rendered the expected returns (Lerner, 2010; tinyurl.com/k4t7817), either due to design or implementation issues. Further attention is required to understand the challenges related to technology-based entrepreneurship (S. A. Shane, 2009; tinyurl.com/lkejdct).

The operating structure of most policy-promotion programs often assumes that resource limitations are the main constraint on the future exploitation success of entrepreneurial opportunities (Lerner, 2010; tinyurl.com/ k4t7817). Following a perspective in line with a discovery view of opportunities (Alvarez and Barney, 2007; tinyurl.com/kcwsn3a), policy-promotion programs might expect entrepreneurs to act upon objective opportunities, identifying and organizing the needed resources to exploit such opportunities. Nevertheless, the design of such initiatives is currently under question (S. A. Shane, 2009; tinyurl.com/lkejdct). Although many perceive these initiatives as likely to satisfy the resource and input needs of low-profile entrepreneurs, the initiatives struggle to efficiently promote technology-based entrepreneurship. Overall, this situation results in poor economic returns for the initiatives and thus low economic returns and social impact for the policy maker (S. A. Shane, 2009; tinyurl.com/lkejdct), putting under stress the initial assumptions of the program design. 


\section{Exploring the Construction of Technology-Based Entrepreneurial Opportunities}

Ferran Giones, Zhao Zhou, Francesc Miralles, and Bernhard Katzy

Prior research on what other factors and processes could influence technology-based entrepreneurship has put the focus on the interactions between the entrepreneur, the technology, and the environment. Scholars have described technology contexts as "high-velocity" environments (Eisenhardt, 1989; tinyurl .com/nxcbzr5) that are inherently dynamic (Clarysse et al., 2011; tinyurl.com/mjxlcxm). In this context of high uncertainty, successful technology-based ventures are seen to heavily depend on the outcomes of actions by entrepreneurs (McMullen and Shepherd, 2006; tinyurl.com/ ktjspta) and their ability to not only recombine resources but also tolerate a higher degree of uncertainty (see McMullen and Shepherd, 2006; tinyurl.com/ktjspta) or, as other authors have suggested, accept the unknowns and the unexpected as part of the future (Sarasvathy, 2001; tinyurl.com/cmjpxg).

Consistent with this view, an emergent stream of literature proposes to further explore the preliminary stages of opportunity enactment, aiming to gain a better understanding on how early actions taken by the entrepreneur might favour the construction or creation of opportunities (Alvarez and Barney, 2007: tinyurl.com/ kcwsn3a; Klein, 2008: tinyurl.com/kpaf8vj). Thus, instead of focusing on the actions that occur once an objective opportunity has been identified, we focus on actions by entrepreneurs to advance from subjective business ideas into an objectified opportunity, following what would be described as an opportunity-construction process (Wood and McKinley, 2010; tinyurl.com/k8xysv8).

This research uses an inductive field study with six technology-based entrepreneurship cases to study the opportunity-objectification process, which can be observed as technology-based business ideas evolve into objective market opportunities (S. Shane, 2012; tinyurl.com/aznwf4n). The findings highlight the influence of initial social interactions in accelerating the muchneeded objectification of the opportunity, transforming the entrepreneur's and stakeholders' perceptions of the initial business idea. The results provide support for fine-grained, customized policy initiatives to foster the development of technology-based entrepreneurship.

\section{Literature Review}

In public and private institutions, an increasing awareness of the influence of entrepreneurial dynamism on economic growth (van Stel et al., 2005; tinyurl.com/ kg68hvu) has been reflected in the widespread adoption of policies to promote entrepreneurial ventures (Gilbert et al., 2004; tinyurl.com/klnrrkm). Nevertheless, scholars have identified that such policies mostly focus on providing basic resources to entrepreneurs at a subsidized price (Lerner, 2010: tinyurl.com/k4t7817; S. A. Shane, 2009: tinyurl.com/lkejdct). Such standardization has generated mixed results, and scholars argue that the impact of such programs on high-growth and high-potential technology-based entrepreneurship has been rather limited (S. A. Shane, 2009: tinyurl.com/lkejdct). Although low-profile ventures have been attracted and created as a result of standardized promotion policies, the excessive focus on making the entrepreneurship inputs less costly and easier to access (Lerner, 2010; tinyurl.com/ k4t7817) has actually excluded projects with high levels of risk and uncertainty.

The institutionalized view of how entrepreneurship works (Honig and Karlsson, 2004; tinyurl.com/mfew3cu) favours the design of promotion policies that assume the entrepreneur's ability to identify opportunities. Thus, it is arguable that support should be focused in post-opportunity stages to facilitate resource appropriation, for example by supplying office space, $R \& D$ grants, or legal advice at reduced prices. The institutionalized view is rooted in the assumptions described in the discovery view of opportunities (Alvarez and Barney, 2007: tinyurl.com/kcwsn3a; S. Shane and Venkataraman, 2000: tinyurl.com/ljc2z31). The discovery view perceives entrepreneurship as a process of uncovering objective opportunities visible to those that have the prior knowledge and resources to "discover" them (S. A. Shane, 2001; tinyurl.com/n8zv5oj).

The discovery view of opportunities describes entrepreneurial processes where entrepreneurs are able to predict - with some accuracy - future outcomes. In this sense, the entrepreneur's ability to gather information and plan their actions accordingly is seen as a success factors for venture development (Delmar and S. A. Shane, 2003: tinyurl.com/lgs634z; S. A. Shane and Delmar, 2004: tinyurl.com/n4wmij9). In other words, the entrepreneur's capacity to understand what resources and actions are needed to produce the desired effects helps to explain some of the differences between successful and non-successful entrepreneurs.

As a result, it is not uncommon to see public agencies and institutions with a mission to promote entrepreneurship, endorsing the elaboration of a formal business plan (Karlsson and Honig, 2007; tinyurl.com/msmxvj6). However, researchers have observed that, in some cases, entrepreneurs rarely use or even review their 


\section{Exploring the Construction of Technology-Based Entrepreneurial Opportunities}

Ferran Giones, Zhao Zhou, Francesc Miralles, and Bernhard Katzy

business plans after they have submitted them (Bygrave et al., 2008; tinyurl.com/mtamr4e). Apparently, these entrepreneurs feel that their business plan has little functional value beyond its role in fulfilling a formal requirement (Kirsch et al., 2009; tinyurl.com/msaousz).

\section{Opportunity objectification in technology-based entrepreneurship}

Describing the actions of technology-based entrepreneurs is difficult using the discovery view of opportunities because the technology context challenges the understanding of entrepreneurship as a process that has "plan/design" and "action" as separate and sequential activities (Baker et al., 2003; tinyurl.com/mj55kcd). The a priori technology-related uncertainty and the often unclear or inexistent market (Teece, 2010; tinyurl.com/oduv9wl) make it cumbersome for technologybased entrepreneurs to advance from their early subjective idea into an objectified opportunity.

Subjective business ideas belong to the individual judgment of a situation, based on prior knowledge and individual motivations, usually emerging in a context of doubt and uncertainty (Shepherd et al., 2007; tinyurl.com/jvwrtvn). Subjective business ideas may gain objectivity and realism: as they are described and acknowledge by third-persons, they may evolve into objective business opportunities, ready to be tested in the market (S. Shane, 2012; tinyurl.com/aznwf4n).

In contrast with environments that are well described using the discovery view, technology-based entrepreneurship is characterized by uncertainty (see McMullen and Shepherd, 2006; tinyurl.com/ktjspta), not only in the exploitation paths of a given technology (Gruber et al., 2008; tinyurl.com/nry3zox) but also in the early steps of conceptualizalizing the technological opportunity. At this early stage, potential technology-based ideas remain untapped as the entrepreneur struggles to gain a minimum social validation (Shepherd et al., 2007; tinyurl.com/jwwrtvn) that would promote the subjective idea into an objective opportunity.

The perceived positive value of repeated interactions within a relevant context (including interactions with the potential market, stakeholders, peers, etc.) has favoured the emergence of alternative theoretical perspectives, including effectuation, bricolage, and creation theory (Sarasvathy, 2001: tinyurl.com/cmjpnxg; Baker and Nelson, 2005: tinyurl.com/c6svx2e; Alvarez and Barney, 2007: tinyurl.com/kcwsn3a). Overall, these perspectives aim to explain how, regardless of the entrepreneur's initial stock of resources, learning and decision-making capabilities can be success factors for constructing entrepreneurial ventures and new markets (Jones et al., 2011: tinyurl.com/knpwrje; Dew et al., 2010: tinyurl.com/kmmohh6).

\section{Constructivist view of entrepreneurship}

In contrast with causal decision-logic perspectives embedded in the discovery view, the approaches described in the previous section draw support from evolutionary theories and embrace a constructivist view of entrepreneurial opportunity development (Wood and McKinley, 2010; tinyurl.com/k8xysv8). This alternative theoretical perspective proposes to complete our current understanding of entrepreneurs' actions in the early stages of opportunity development, by observing the motivations and effects of the social-interaction processes of entrepreneurs. Hence, the attention now shifts to how an entrepreneur's actions introduce changes in the idea conceptualization and, at the same time, modify the potential venture stakeholders' assessment of its validity as an objective opportunity.

Despite the emergence of alternative views of the entrepreneurship process in highly uncertain contexts (Fisher, 2012; tinyurl.com/c8yb7rd), little is known about the organization of activities and processes that build the initial opportunity conceptualization in technologybased-ventures. In particular, this research aims to explore and gain a better understanding of the mechanisms used by technology-based entrepreneurs to overcome the challenges of opportunity conceptualization as they evolve their initial business idea into an objective opportunity.

\section{Method and Data}

Consistent with our exploratory objective, we drew upon an inductive multiple-case field study design (Yin, 2003; tinyurl.com/7ywkcpy). Multiple-case studies offer support for contrasted evaluation of the initial findings, adding evidence to otherwise singular results (Eisenhardt and Graebner, 2007; tinyurl.com/ckek69c) produced with single-case research.

In addition, case-study data, rich in contextual elements, provide a lively reflection of the motivations and actions performed by entrepreneurs. This approach offers an opportunity to explore questions that have not yet been addressed in the existent literature (Siggelkow, 2007; tinyurl.com/lxx9f4f). The interpretative nature of the method fits well with the intention of capturing the entrepreneur's perceptions of the stakeholders' participation in the social construction of the opportunity. 


\section{Exploring the Construction of Technology-Based Entrepreneurial Opportunities}

Ferran Giones, Zhao Zhou, Francesc Miralles, and Bernhard Katzy

Previous research linking social context and entrepreneurial opportunities have followed quantitative approaches either using panel or survey data (Dimov, 2007: tinyurl.com/lweyd78; Newbert and Tornikoski, 2011: tinyurl.com/lpgn4hm) and have not been able to uncover the actual motivations and contextual influences of entrepreneurs' actions. This research is designed to provide additional insights that benefit from a rich contextualization of entrepreneurship theories, as described by Zahra (2007; tinyurl.com/kwqamf3) and Welter (2011; tinyurl.com/m584brj), extending the constructivist perspective contributions in the entrepreneurship field (Wood and McKinley, 2010; tinyurl.com/k8xysv8).

\section{Sample}

The selected cases depict the opportunity-conceptualization process of six technology-based entrepreneurs that are pursuing complex and uncertain technology opportunities. Three of the cases were part of a Chinese technology-entrepreneurship program, and the other three cases were part of a Spanish program (Table 1). The case selection introduces significant cultural and environmental differences to explore the phenomena and the contextual effects (Rousseau and Fried, 2001; tinyurl.com/m9haomo) at a global scale, with the intention of capturing the sources of variability of the phenomenon beyond a singular geographic location.
As much as possible, we selected ventures with similar opportunities. All of the cases were in high-technology fields: wireless telecommunications, electronics, and software. We also took into account potential differences in venture development to mitigate perceptual differences due to self-reporting biases. For example, none of the entrepreneurs interviewed had started their venture more than three years prior to the start of the study.

In addition, the entrepreneur's prior experience was used as a case-selection variable, because previous research has suggested that entrepreneurs experience might influence their decision-making and operating logics (Dew et al., 2009; tinyurl.com/kg6gw9t). Therefore, we included a mix of profiles from experienced and novice entrepreneurs in the final multiple-case study.

\section{Data collection}

We gathered the data through interviews and direct observation conducted between March 2009 and June 2010. The interviews with the venture entrepreneur lasted between 45 to 90 minutes and included questions relating to the entrepreneur's background, the venture's evolution, and related technological background. To further illustrate the study cases, we obtained additional information about the cases through secondary sources.

Table 1. Sample of entrepreneurs' venture description

\begin{tabular}{|c|c|c|c|c|}
\hline Venture Name & Entrepreneur Profile & Technology & Initial Idea & Objectified Opportunity \\
\hline $\begin{array}{l}\text { Winet } \\
\text { (Spain) }\end{array}$ & $\begin{array}{l}\text { Novice entrepreneur: } \\
\text { academic/technology } \\
\text { background }\end{array}$ & Communication protocol & $\begin{array}{l}\text { Communication protocol } \\
\text { for emergency data } \\
\text { exchange }\end{array}$ & $\begin{array}{l}\text { Proximity communications } \\
\text { solution to engage retail } \\
\text { customers }\end{array}$ \\
\hline $\begin{array}{l}\text { Powchip } \\
\text { (Spain) }\end{array}$ & $\begin{array}{l}\text { Novice entrepreneur: } \\
\text { academic/technology } \\
\text { background }\end{array}$ & $\begin{array}{l}\text { Design for integrated } \\
\text { circuits }\end{array}$ & $\begin{array}{l}\text { Low power consumption } \\
\text { asynchronous chips design }\end{array}$ & $\begin{array}{l}\text { New chip design for mobile } \\
\text { devices (design method } \\
\text { training and full solutions) }\end{array}$ \\
\hline $\begin{array}{l}\text { DigiTV } \\
\text { (Spain) }\end{array}$ & $\begin{array}{l}\text { Experienced entrepreneur: } \\
\text { technology and market } \\
\text { background }\end{array}$ & $\begin{array}{l}\text { Digital television broadcast } \\
\text { coding }\end{array}$ & $\begin{array}{l}\text { Digital television changes } \\
\text { needs in the broadcaster- } \\
\text { user systems }\end{array}$ & $\begin{array}{l}\text { Technological platform to } \\
\text { support broadcasters and } \\
\text { viewers needs for tailored } \\
\text { content on demand }\end{array}$ \\
\hline $\begin{array}{l}\text { Hying } \\
\text { (China) }\end{array}$ & $\begin{array}{l}\text { Novice entrepreneur: } \\
\text { technology background }\end{array}$ & $\begin{array}{l}\text { Chemistry treatment for } \\
\text { semi-conductor production }\end{array}$ & $\begin{array}{l}\text { Identification of gaps in } \\
\text { existing treatments }\end{array}$ & $\begin{array}{l}\text { Disruptive solution for } \\
\text { semi-conductor } \\
\text { manufacturers }\end{array}$ \\
\hline $\begin{array}{l}\text { Capital } \\
\text { (China) }\end{array}$ & $\begin{array}{l}\text { Novice entrepreneur: } \\
\text { technology background }\end{array}$ & X86-based CPU & $\begin{array}{l}\text { Computing power for } 3 G \\
\text { mobile future }\end{array}$ & $\begin{array}{l}\text { X86 CPU design for mobile } \\
\text { Internet devices }\end{array}$ \\
\hline
\end{tabular}




\section{Exploring the Construction of Technology-Based Entrepreneurial Opportunities}

Ferran Giones, Zhao Zhou, Francesc Miralles, and Bernhard Katzy

We recorded and transcribed the interviews into a standard template to facilitate analysis. For each of the cases studied, we wrote a case story, weaving together the data obtained through different research sources following a chronological description of the entrepreneur's actions and venture evolution.

For the purposes of this article, the names of the ventures have been changed to protect confidentiality.

\section{Data analysis}

We began the data analysis with no a priori hypotheses; despite having some theoretical insights on the constructs that were the subject of analysis, it was the descriptions provided by the informants that guided our initial cases analysis. We captured the stories that started with the first thoughts of their "initial idea" and the early actions, events, and changes that led to "opportunity objectification".

The construct of "opportunity objectification" emerged from the data as the first third-party validation that there was an opportunity. In some cases, the validation came through an informal interaction with a potential customer that was part of the direct entrepreneurs' social network; in other cases, it emerged through discussing the business idea with industry peers. In all sampled cases, the objectification of the opportunity was perceived as a trigger event for the further development of the venture. In other words, this step produced a mindset change in the entrepreneur's perception of the business idea and the overall assessment of the opportunity's viability (Wood and McKinley, 2010; tinyurl.com/k8xysv8).

We used individual case stories to conduct the first rounds of analysis, in which we attempted to make sense of the actions and events that build the opportunity-conceptualization process (i.e., evolving the business idea into the objectified opportunity). As relevant levers and activities started to emerge in the first cases sampled, we added further cases to complete and contrast the initial findings until we reached a saturation point where no new insights were uncovered. Further analysis included a cross-case comparison to either support or capture additional sources of variability for our initial findings.

In parallel to the data-iteration process, we sustained a regular contrast between data-driven findings and literature sources that could provide support and refine our interpretation of the data.

\section{Results}

Technology-based entrepreneurship is seen as a process where entrepreneurs are willing to bear high levels of uncertainty (McMullen and Shepherd, 2006; tinyurl.com/ktjspta). The initial business idea is often seen to pivot around an untested technology or an imagined disruptive market solution. Technology-based ventures often combine both elements, meaning there is uncertainty in both the technology and the market. So, how do entrepreneurs mitigate this uncertainty to start exploring the viability of their business idea? What actions and mechanisms accelerate the process of opportunity conceptualization? How does the opportunity become objectified?

In most of the cases we studied, the source of the business idea was an ongoing research project that either produced a technology that offered additional applications or offered evidence of a need for better technology-based solutions. In the words of Powchip's founder: "I've been doing research in the field of asynchronous circuits for many years... only in the last few years power consumption has begun to be important issue, as the market for mobile devices has developed". Or, as the founder of Hying described: "While working as a chemistry analyst, I found technology defects in the existing treatment processes for semi-conductors manufacturing." The entrepreneur is placed in an unknown situation, with an idea at hand but, in most of the cases studied, with limited prior knowledge and experience. It is in these cases where the discovery view can only partially explain the construction process that entrepreneurs are seen to start.

The data we collected shows that, instead of being blocked by uncertainty or risk perception, the entrepreneur moved ahead without a priori planning. As Winet's founder stated: "I started working from scratch on a new technological solution, changing everything." Consequently, the path towards the opportunity requires the entrepreneur to bear the burden of high uncertainty (McMullen and Shepherd, 2006; tinyurl.com/ ktjspta), and initial predictive efforts are seen to have limited value. In this context, the entrepreneur relies on their ability to make things happen, using the lenses of the creation or effectuation perspectives (Sarasvathy, 2001; tinyurl.com/cmjpnxg). This is a situation where the entrepreneur's capacity to produce the desired effects with the available (limited) resources become a key factor to understand how the initial idea is transformed into a real opportunity. 


\section{Exploring the Construction of Technology-Based Entrepreneurial Opportunities}

Ferran Giones, Zhao Zhou, Francesc Miralles, and Bernhard Katzy

\section{The ideation process}

Previous research has highlighted the potential influence of an entrepreneur's pre-existent networks in the conceptualization of the opportunity (Wood and McKinley, 2010; tinyurl.com/k8xysv8). In fact, the mismatch between the entrepreneur's individual knowledge and the opportunity-related needs becomes the trigger of the first key process in the emergence of the opportunity: iteration with knowledgeable peers. The entrepreneur's initial identification of peers with whom to exchange early thoughts and information on the initial idea fits more with an effectuation than a causation perspective (Sarasvathy, 2001; tinyurl.com/cmjpnxg). Our results suggest that entrepreneurs mostly rely on the contacts from within their existing network of direct personal ties that are closest and easiest to contact, without assessing the appropriateness of the contacts. As Powchip's founder stated: "It was with a research contact that the idea came out." Similarly, Winet's founder recalled that validation for the idea came about when "talking with an entrepreneur in integrated circuits design that I knew from prior joint-research projects".

Nevertheless, the data showed a slightly different decision path for the experienced entrepreneurs. As suggested by Baron and Ensley (2006; tinyurl.com/l4pl8kt), experienced entrepreneurs were observed to benefit from their pattern-recognition abilities when actually selecting the appropriate peers from their pre-existent network to engage in the opportunity conceptualization. In intentionally employing a selection mechanism, experienced entrepreneurs benefit from their more-balanced personal network, built with both technology-research peers, and market/industry peers. DigiTV's founder recalled that: "It was my previous business partner that insisted on exploring together the changes that Internet and digital TV would produce in the industry". Together, these peers would go on to refine the idea together in a cafeteria: "We met for over a month to draw up our business plan and technological architecture." We did not observe this level of detail in the cases with novice entrepreneurs.

An additional difference between experienced entrepreneurs and novice entrepreneurs was observed: experienced entrepreneurs would simultaneously leverage various processes of iteration with knowledgeable peers, whereas novice entrepreneurs were seen to follow a more sequential process of action. Consistent, with Dew and colleagues (2009; tinyurl.com/kg6gw9t) and Politis (2008; tinyurl.com/k3umurs), this observation supports the idea that experienced entrepreneurs take ad- vantage of specific market and technology knowledge, and they benefit from being familiar with the mechanisms that would accelerate the idea-refinement process.

\section{From ideation to opportunity objectification}

The constructivist view of entrepreneurship proposes to observe the entrepreneur's influence in the cognitions and beliefs of outside actors involved in the process (Wood and McKinley, 2010; tinyurl.com/k8xysv8). In this sense, the opportunity-conceptualization process would not be described as shedding light into an objective reality, but as an ongoing transformation the perceptions of entrepreneurs and stakeholders regarding the validity of the idea through a consensus-building process that drives toward opportunity objectification.

If the initial exchanges of information through interaction with knowledgeable peers were seen as a source of early validation and informal feedback, the consensusbuilding process would bring the social exchange into a more formal level. In the words of Winet's founder: "We started to look for people with reputation in the field as advisors." Therefore, this view reflects rational design planning before execution (Baker et al., 2003; tinyurl.com $/ \mathrm{mj} 55 \mathrm{kcd}$ ) and acknowledges, even at this early stage, the value of reputation (see Fischer and Reuber, 2007; tinyurl.com/mse2j65). Besides this oriented action to consensus building, the data from our cases reveals two parallel sub-processes: technology assessment, as "evaluating the technology, if it has sense, if it is viable" (Powchip founder) and market "sensemaking" (Weick et al., 2005; tinyurl.com/kobg2ad) between the technology and the intended opportunity. As Powchip's founder pointed to the value of "engaging with potential customers to assess whether your idea could fit". At this point, the influence of the feedback is crucial for the entrepreneur's decision about whether to keep advancing or abandon the opportunity. In the words of Hying's founder: "The encouraging feedback I got from the conversations with colleagues and experts at the Chinese Academy of Science made me feel more confident about the viability of my technological concept."

Therefore, in technology-based entrepreneurship, the conceptualization of the opportunity through consensus building involves gaining social legitimacy. At a first level, this means achieving a technology assessment and an acceptable fit between an initial idea and a dynamic market. DigiTV's founder recalled that, "the initial idea has suffered multiple changes... you cannot get stuck in an idea and stop listening or looking at the market". On a second level, there is a need to gain so- 


\section{Exploring the Construction of Technology-Based Entrepreneurial Opportunities}

Ferran Giones, Zhao Zhou, Francesc Miralles, and Bernhard Katzy

cial legitimacy to further advance in the consensusbuilding process; as Powchip's founder recalls, stakeholders are seen to expect that "a third-party evaluates the technology and raises the confidence level on the idea". At this point, the formal involvement of institutions - private or public - mitigates the stakeholders' perception of uncertainty. DigiTV's founder experienced this benefit with "the full institutional support of the university"; Capital's founder experienced this benefit with "the network we built from the Association of Chinese Engineers in Silicon Valley".

\section{The context of opportunity objectification}

The constructivist view posits that opportunity objectification channels an entrepreneur's behaviour towards opportunity enactment (Wood and McKinley, 2010; tinyurl.com/k8xysv8), thereby acknowledging the change in the entrepreneur's mindset and the stakeholders' perception as the subjective opportunity gains third-party acceptance (Shepherd et al., 2007; tinyurl.com/jvwrtvn). However, the cases we studied suggest that the impact of the opportunity objectification on the behaviour of the entrepreneur and stakeholders is highly mediated by their spatial and institutional context. The results show that, regardless of the public or private institutional support gained in the consensus-building process, the entrepreneur's early needs for explicit support (e.g., external funding) to advance on the objectified opportunity would raise unexpected hurdles. In the words of Powchip's founder: "Here we are more conservative; we study it more, it is a much longer process". Winet's founder compares his own context to the context in the United States, where "there is a culture, a network of people that mixes investors and technology specialists".

In the cases of Winet and Powchip, these hurdles led to the decision of registering part of their companies' future operations in the United States; even when this action meant that they had to follow again a consensus-building processes to gain legitimacy in a new context. In other cases (i.e., Hying, Capital, and Mars), the entrepreneur would delay bringing to market the objectified opportunity, to instead engage in further consensus-building processes to secure explicit support and access to institutional mechanisms from regional institutions.

\section{Conclusions}

With this research, we posit that technology-based entrepreneurship benefits from social interaction mechanisms. In particular, we explore the value of the iteration with knowledgeable peers and consensus-build- ing processes in the conceptualization of an idea into an objective opportunity.

Our results provide empirical support to the nascent constructivist view of technology-based entrepreneurship and highlight the value of contextualization Welter (2011; tinyurl.com/m584bri) in the study of the social actions of entrepreneurs. Thus, our findings provide a complement to the traditional discovery view and introduce a description of the bidirectional processes that occur in the opportunity-objectification process and its implications for technology-based entrepreneurship.

Prior research has outlined the explanatory potential of a social construction view on technology entrepreneurship (Wood and McKinley, 2010; tinyurl.com/k8xysv8); this article uses a multiple-case study approach to uncover different mechanisms and processes of opportunity construction depending on the entrepreneurs' experience and institutional environment.

However, this research is not without limitations. First, our observations contain a survivor bias; our sample only contains entrepreneurs that managed to advance to opportunity enactment and venture development. Second, our findings only reflect the cases observed and do not have prescriptive power, despite the crosscase analyses offered inter-case support. Further research following the constructivist view would enhance the empirical support and contrast the validity of our exploratory findings.

\section{Implications}

Our research findings have both theoretical and practical implications. From an academic point of view, our results bring data that support the position of the constructivist view as a source of valuable information to understand technology-based entrepreneurship. Thus, we contribute to the growing literature on the socialconstruction processes of entrepreneurial opportunities. In addition, our results suggest that we are observing a phenomenon that crosses national boundaries; regardless of cultural differences, the conceptualization of the technology-based opportunity in diverse geographic contexts has more similarities than expected.

For entrepreneurs and organizations involved in fostering technology-based entrepreneurship we add value in two different dimensions. Firstly, our data suggests that entrepreneurship-promotion initiatives should make greater emphasis on the opportunity-objectification process. In technology-based entrepreneurship, 


\section{Exploring the Construction of Technology-Based Entrepreneurial Opportunities}

Ferran Giones, Zhao Zhou, Francesc Miralles, and Bernhard Katzy

we have seen that the objectivity of the idea is by itself a complex construction process; therefore, it would benefit from additional support mechanisms in comparison to other types of business ideas in which the objectivity of the opportunity is not embedded in uncertainty. Secondly, standard mechanisms derived from the institutionalized logic of early planning before execution might continue to produce low returns in technologybased entrepreneurship, unless the planning instruments are modified and become more receptive to the iteration and consensus-building mechanisms that are seen to benefit the opportunity conceptualization and raise the commitment of stakeholders.

\section{Acknowledgments}

This article is based on a paper presented at the ISPIM 2012 Conference. The authors wish to thank seminar participants at the NITIM Research Seminars at CeTIM Munich and La Salle - Ramon Llull University in Barcelona, as well as conference participants at ISPIM 2012 for their valuable feedback and advice. This works was supported by CeTIM and La Salle - Ramon Llull University research grants.

\section{About the Authors}

Ferran Giones is a research assistant at La Salle Innova Institute - Ramon Llull University in Barcelona, Spain. He has Bachelors and Masters degrees in Business Administration from ESADE Business School in Barcelona. Ferran's professional background is in management consulting and international business-operations development. In recent years, he has been working in the areas of entrepreneurship and innovation, closely studying how entrepreneurs' ventures emerge in dynamic environments under high uncertainty conditions.

Zhao Zhou is a PhD candidate at the Center for Technology and Innovation Management (CeTIM) at Leiden University, The Netherlands. His research interests are focused on the regional innovation system, technology-based entrepreneurship, and technology transfer. He has published in several international journals.
Francesc Miralles leads the La Salle Innova Institute in Barcelona, Spain, and is Professor of IS strategy, Innovation Management, and Research Methods in La Salle BES, at La Salle Campus Barcelona - Ramon Llull University. He has a PhD from the Polytechnic University of Catalonia and an MBA from ESADE. Before joining La Salle BES - URL, he was Executive Director in the Information Society Observatory of Catalonia (FOBSIC). Francesc was Professor and Dean at the University Pompeu Fabra Barcelona. His current research interests are in the area of information technology management, innovation management, and entrepreneurship. He has participated in several international research projects funded by the European Commission, the CYCIT (Spanish government), and the CENIT programme (Ministry of Science \& Innovation). For three years, Francesc was a member of the executive committee of the International Conference on Information Systems (sponsored by AIS). He was co-chairman of the ICIS'02 held in Barcelona in December 2002.

Bernhard R. Katzy is Professor of Technology and Innovation Management at the University BW $\mathrm{Mu}-$ nich in Germany and Leiden University in The Netherlands. He is founder and director of the Center for Technology and Innovation Management (CeTIM). Bernhard was invited to be the keynote speaker at the launch event of the European Living Lab movement in December 2006, is leading the knowledgeworker living lab (one of the first wave of living labs), and is founding member of ENoLL, the association of living labs. He started his professional career with an apprenticeship as car mechanic and later earned Master of Science degrees in electrical engineering and business management. He holds a $\mathrm{PhD}$ in industrial management from University of Technology (RWTH) Aachen in Germany and a second Ph.D. (Habilitation) in general management and technology management from University of St. Gallen, Switzerland. His research interest is about entrepreneurial management of fast-growing high-tech firms and the management of strategic change in the transition to the information age.

Citation: Giones, F., Z. Zhou, F. Miralles, and B.R. Katzy. 2013. From Ideas to Opportunities: Exploring the

Construction of Technology-Based Entrepreneurial

Opportunities. Technology Innovation Management Review. June 2013: 13-20.

Keywords: technology entrepreneurship, constructivist view, entrepreneurship policy 